\title{
WIND TURBINES EQUIPPED WITH SELF-EXCITED INDUCTION MACHINE IN AUTONOMOUS MODE : ANALYTICAL AND NUMERICAL STARTING STUDIES
}

\author{
H. ROISSE ${ }^{1}$, G. PESET $^{2}$, V. AUTIER ${ }^{1}$, J.F. BRUDNY ${ }^{1}$ \\ ${ }^{1}$ Laboratoire Systèmes Electrotechniques et Environnement (L.S.E.E.) \\ Faculté des Sciences Appliquées - Technoparc Futura - 62400 Béthune - France \\ Phone : (33) 3.21.63.72.18 / Fax : (33) 3.21.63.72.11 \\ e-mail : herve.roisse@univ-artois.fr \\ ${ }^{2}$ Delstar - Montréal - Québec - Canada and \\ Groupe Eolien de l'Université du Québec à Rimouski
}

\section{Introduction}

This paper deals with the definition of a new procedure devoted to the analysis of an autonomous self-excited induction generator (IG) comportment. First, for the steady state, a new single phase equivalent scheme is proposed. Then, this scheme is used to analyze the selfexcited starting. Numerical study based on space phasor theory, as well as experiments, allow to validate the theorical approaches.

Keywords : Wind machine, induction machine, selfexcited, autonomous mode.

\section{Steady state study}

Developments, which concern the steady state, lead to define a new equivalent single phase scheme (figure 1) which allows to obtain better results than the classical approach using the traditionnal equivalent single phase scheme of induction machine.

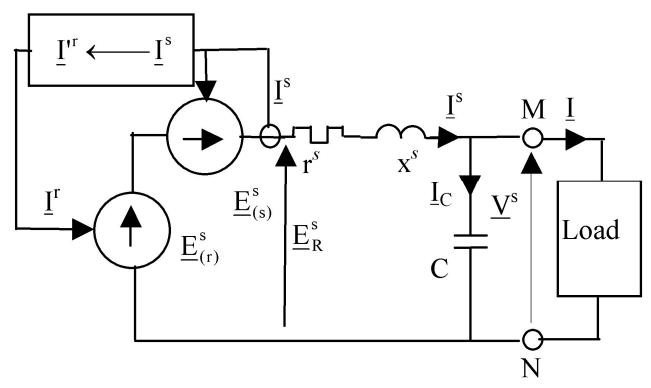

Fig. 1. New equivalent single phase scheme

\section{Transient study}

In order to determine the critical build up speed $\omega^{\prime}$ c of the rotor, a physical approach, using the new equivalent scheme proposed, allows to solve analytically the problem. It can be shown, for resistive load $\mathrm{R}$, that $\omega_{\mathrm{c}}^{\prime}=\left[\omega_{0}^{2}-\frac{1}{4 \mathrm{R}^{2} \mathrm{C}^{2}}\right]^{\frac{1}{2}}$ with $\omega_{0}=\left[\frac{1}{\mathrm{~L}_{\mu} \mathrm{C}}\right]^{\frac{1}{2}}$, where $\mathrm{L}_{\mu}$ is the magnetizing inductance of the machine.
A numerical analysis, based on the space vector theory, is then presented in order to confirm the physical considerations. This numerical study allows to follow the start of a wind machine as presented at figures 2 and 3 .

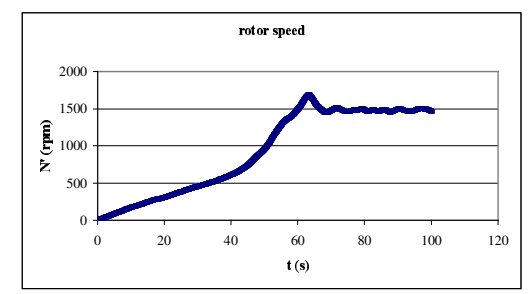

fig. 2. Time evolution of the IG rotor speed

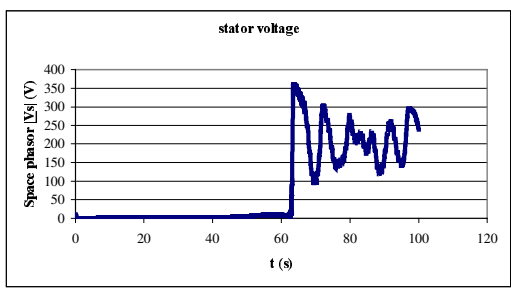

fig. 3. Time evolution of stator voltage space vector

\section{Conclusion}

The predetermined values by the theoretical approach are very closed to the experimental or numerical ones. Consequently the relationships thus established allow to an ingineer to define quickly the wind machine comportment in autonomous mode and namely its possibilities to start according to values of capacitor and the nature of the load.

\section{References}

[1] Siegfried Heir, "Wind energy conversion system", edition John Whiley and Sons, 1998.

[2] S. Rajakaruna and R. Bonert, "A technique for steadystate analysis of self-excited induction generator with variable speed", IEEE Transactions and Energy Conversion, Vol. 8, N4, pp. 757-761, December 1993.

[3] R.J. Harrington, F.M.M. Bassiouny, "New approach to determine the critical capacitance for self-excited induction generators", IEEE Transaction on Energy Conversion, Vol. 13, N³, pp. 244-249, september 1998. 